\title{
A NOTE ON PULSATING MANUBRIAL TUMOUR
}

\author{
BY \\ THOMAS LEWIS \\ From University College Hospital \\ Received June 22, 1940
}

In the two cases that are here described pulsating tumours over the upper part of the sternum simulated pointing aneurysms, but were in reality secondary deposits from neoplasms elsewhere.

\section{Case 1}

In December 1932 a man of 48 was sent to me for an opinion. He said that 15 months previously, while engaged in work as a house demolisher, he fell down two stories through a shaft. He broke an arm, a leg, and ribs, and had been unable to work since the accident. His chief complaints were of shortness of breath and of pain over the region of the upper part of the sternum, radiating to the shoulder and down the arms to the elbows, though unrelated to exercise. He came diagnosed as a case of aneurysm of the aorta, and a second opinion was required because he was claiming compensation for injury arising out of his employment. On stripping him I found an obvious swelling over the manubrium sterni. It extended from the top of the manubrium to the upper border of the first rib, and a little beyond the sides of the sternum laterally. The rounded lump projected about $1.5 \mathrm{~cm}$.; the skin over it was not discoloured ; there was visible and palpable pulsation, the tumour expanding with each heart beat. A long but inconspicuous systolic murmur was audible over the tumour. The Wassermann reaction was positive. The pulses were equal, and there were no pressure symptoms or signs. At first there seemed little reason to question the diagnosis, but closer examination gave rise to increasing doubt. The first point to arouse suspicion was the shape of the tumour itself ; in the middle line the mass was hemispherical, but in the first right interspace an inconspicuous flattened tongue projected from it for $2 \mathrm{~cm}$., also pulsating. Moreover, a finger could be carried down behind the sternum a little way without meeting resistance. The second point was that the pulsation of the tumour, when compared with that of the carotid artery, seemed softer and less abrupt than was to be expected, and very slightly but distinctly delayed. He gave incidentally a history of passing a small quantity of blood in the urine on two occasions many months before. The urine was normal, but the blood urea was a little raised. The right kidney was palpable and seemed enlarged. I refused to confirm the diagnosis of aneurysm, believing the tumour to be a new growth. 
I was asked to re-examine the man in March 1934, 15 months later, from the same point of view as previously. His symptoms were unchanged ; so were the signs, except that the manubrial tumour had increased perceptibly in size, and he was thinner. On this occasion, however, X-ray examination detected what was not present before, namely, an abnormal shadow above the level of the knob of the aorta, extending also above the level of the manubrium, and a clear picture of a secondary deposit in the upper part of the shaft of the left humerus.

The diagnosis was now unmistakably hypernephroma with secondary deposits.

The interest of the case lay, of course, in its original resemblance to pointing aneurysm, and most noteworthy were the relative softness of the pulsation and the slight but perceptible delay in its rise, a delay confirmed at the time by records shown in the figure below.

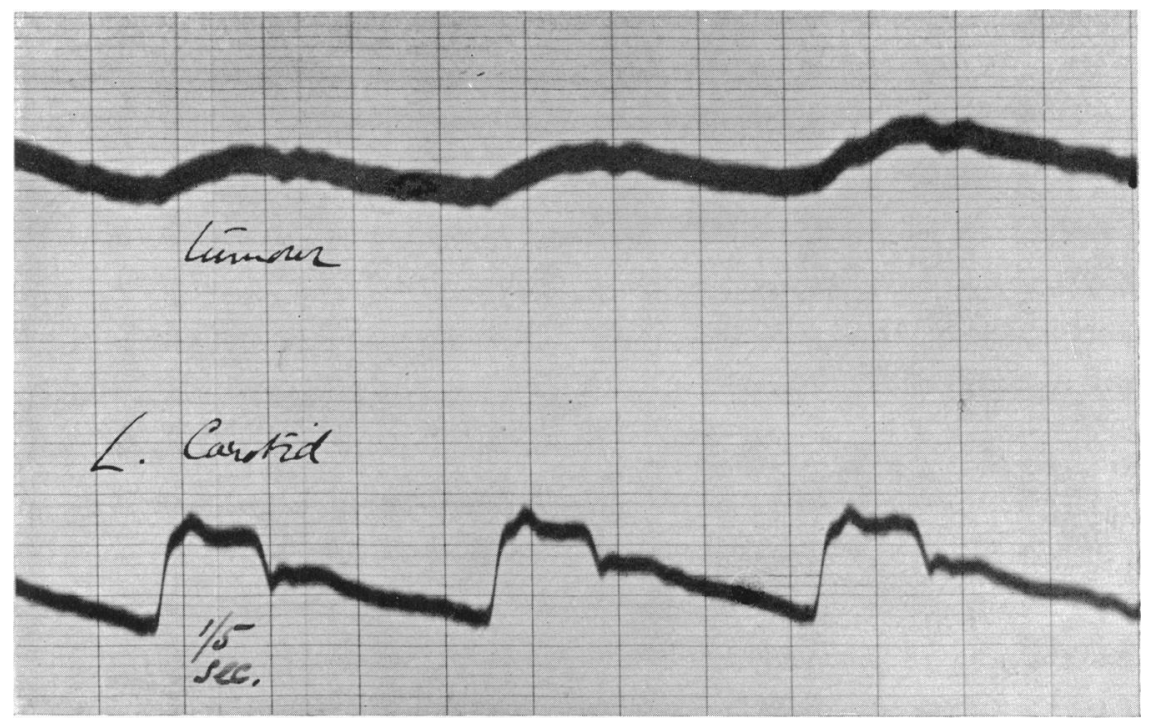

FIG. 1. - The upper curve, taken from over the tumour in the manubrium sterni, indicates that pulsation there was slightly later than the pulsation of the carotid pulse.

\section{Case 2}

In June 1939 a man of 58 years was admitted under my care complaining of hiccough and vomiting of six weeks' duration, the passage of a little blood in the urine for three weeks, and a lump that had developed recently over the upper part of the chest.

He had full signs of tabes dorsalis and a tongue presenting advanced chronic superficial glossitis ; the Wassermann reaction was positive.

A tumour projected over the right sterno-clavicular joint and below it. It was hemispherical, and about $5 \mathrm{~cm}$. in diameter, and pulsated quite distinctly. The heart was much enlarged, and over the tumour a loud systolic murmur was audible. The second right space was dull to percussion, and a tracheal tug was 
detected ; the pulses and pupils were equal, and there were no pressure signs. $\mathrm{X}$-ray examination showed a greatly dilated aorta. The blood pressure was 220 systolic, 140 diastolic; the blood urea shortly rose from $130 \mathrm{mg}$. to $270 \mathrm{mg}$. within a few days, and the man died uræmic. During life the kidneys were not felt, but albumin and occasional red cells were found in the urine.

In demonstrating this patient I remarked upon the unusual softness and slow rise of the pulsation in the tumour, and recalled and summarized the case of hypernephroma previously seen and here described as Case 1. But because this patient had a clear X-ray picture of an enlarged aorta and a tracheal tug, a diagnosis of aneurysm pointing through the chest wall seemed unavoidable, the urinary symptoms being ascribed to renal sclerosis and insufficiency.

At autopsy the heart was found greatly enlarged, the pericardium completely obliterated by old adhesions. The aortic valves were very atheromatous and a little incompetent. The aorta was greatly dilated, and its wall presented gross syphilitic changes. But there was no aneurysmal projection through the sterno-clavicular joint, which was occupied by a deposit of new growth, spreading from the manubrium sterni and secondary to a large hypernephroma of the upper pole of the right kidney. The left kidney was granular on the surface and very fibrotic on section.

\section{Summary}

Two cases are briefly described in which pulsating tumours over the upper part of the sternum in syphilitic subjects seemed to indicate pointing aneurysm. Both tumours were in fact secondary deposits from hypernephroma, though in one case aneurysmal dilatation of the aorta was present as well. The cases are of interest in emphasizing softness and slowness and a slight but just distinct delay in the rise of the pulse in these pulsating neoplasms. 